\title{
Recent progress in soft-templating of porous carbon materials
}

\author{
Laemthong Chuenchom, ${ }^{a b}$ Ralph Kraehnert ${ }^{* a}$ and Bernd M. Smarsly ${ }^{* b}$ \\ Received 22nd December 2011, Accepted 5th July 2012 \\ DOI: $10.1039 / \mathrm{c} 2 \mathrm{sm} 07448 \mathrm{f}$
}

\begin{abstract}
Mesoporous carbons synthesized via a soft-templating approach have attracted much attention due to their easy synthesis and facile control over the derived pore structure. In analogy to soft-templating approaches for mesoporous metal oxides, their synthesis is based on a sequence of forming supramolecular arrangements of precursor molecules with the soft templates, stabilization of the precursor framework by polymerization and finally the removal of the templates. Using micelles of amphiphilic block-copolymers as templates, facile control over the morphology and size of mesopores can be achieved by e.g. controlling size, composition, and concentration of the template polymers or composition and degree of polymerization of the precursor. Moreover, soft templating approaches can be extended to obtain also carbon materials with hierarchical meso- and macroporosity. The additional macroporosity either can result from templating by polymer latex or is induced via macrophase separation. In this review, we describe recent progress and examples in the synthesis and application of mesoporous carbon materials based on soft-templating approaches. Moreover, we reiterate fundamental principles of self-aggregation, highlight proposed synthesis mechanisms and present means of controlling pore size, also in hierarchical meso-macroporous carbon materials.
\end{abstract}

\section{Introduction}

Porous carbon materials provide unique benefits such as high specific surface area and large pore volume in combination with good chemical and mechanical stability. Thus, they are widely

${ }^{a}$ Department of Chemistry, Technical University of Berlin, Straße des 17. Juni 124, 10623, Berlin, Germany. E-mail: ralph.kraehnert@tu-berlin.de ${ }^{b}$ Institute of Physical Chemistry, Justus Liebig University of Giessen, Heinrich-Buff-Ring 58, 35392, Giessen, Germany. E-mail: Bernd. Smarsly@phys.Chemie.uni-giessen.de used in applications such as adsorption, gas storage, separation, catalysis and electrochemistry.

Activated carbon is the most commonly applied material due to its low cost and the possibility of large-scale processing. However, activated carbon features a locally inhomogeneous structure and usually possesses a wide distribution of pore sizes. Moreover, the abundant presence of micropores (size $<2 \mathrm{~nm}$ ) often limits mass transfer and pore accessibility in applications such as adsorption, chromatography and Li-batteries. In particular, when the rapid diffusion of larger molecules into the

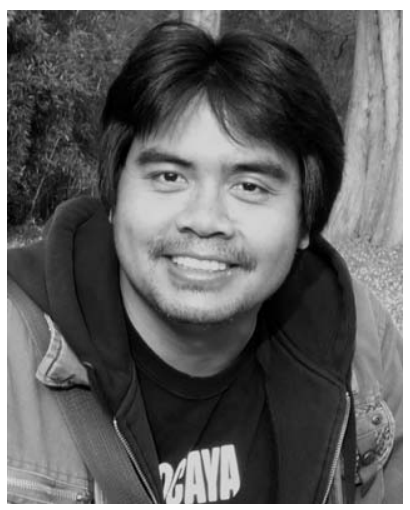

Laemthong Chuenchom
Laemthong Chuenchom received his M.Sc. in Chemistry from Prince of Songkla University, Thailand, with his master thesis on synthesis of porous carbon materials from natural resources. He is pursuing his PhD at both the Technical University of Berlin and the Justus Liebig University of Giessen under the supervision of both Dr. Kraehnert and Prof. Smarsly. His research is focused on mesostructural carbon coatings through soft-templating approaches, and their use for catalysis.

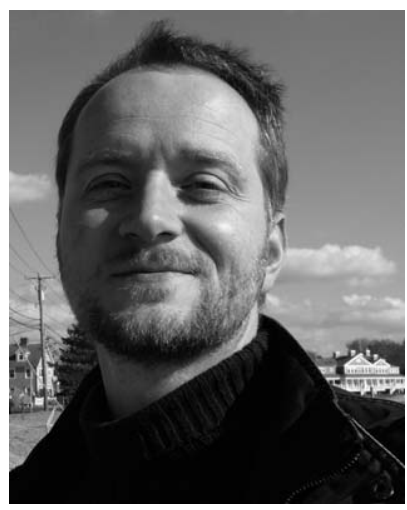

Ralph Kraehnert
Ralph Kraehnert was awarded a degree as Dr.-Ing. in 2005 for research on Pt-catalyzed oxidation of ammonia. Since 2007 he leads an independent junior-research group financed by $B M B F$ and by the DFG Cluster-of-Excellence UNICAT. In 2012, he became an Einstein Junior Fellow of the Einstein Foundation Berlin. He develops methods for a rational design of catalysts and the synthesis of porous oxides, colloidal nanoparticles and catalysts with controllable nanostructure. 
internal surface of porous carbon is required, materials possessing controllable pore dimensions in the size range of mesopores $(2-50 \mathrm{~nm})$ are desirable.

The synthesis of porous carbon materials with high surface area can be achieved by various methods, for instance by catalytic activation of carbon precursors, ${ }^{1,2}$ carbonization of polymer blends containing thermally decomposable components, ${ }^{3}$ as well as the carbonization of resorcinol-formaldehyde aerogels. ${ }^{4}$ However, carbon materials derived from these syntheses often possess a broad pore size distribution. To obtain materials with narrow and controlled pore size distributions, one suitable strategy is the replication of a rigid template material which already possesses controlled mesoporosity. Using this "hardtemplating" approach and mesoporous silica as the template, Ryoo et al. ${ }^{5,6}$ and Hyeon et al. ${ }^{7}$ pioneered the synthesis of ordered mesoporous carbons ("OMC"). Since then, hard templating has been further improved using a variety of mesoporous oxides as described in different reviews, ${ }^{6-15}$ but it also inherits severe drawbacks. In particular, the necessity of removing the inorganic template employing hazardous chemicals such as $\mathrm{HF}$ or $\mathrm{NaOH}$ is a drawback in industrial applications. Moreover, facile control over the pore size and structure of the classical hard-templated OMCs is obstructed by the fact that the carbons' pore system represents the inverse structure of the template porosity, e.g. the wall thickness of the mesoporous oxide determines the pore size of the carbon material. Although demonstrated recently for titania, independent control of the wall thickness remains challenging for many templating oxides. ${ }^{16}$

In contrast, direct soft templating of the carbon material can provide an alternative facile way to control its mesopore structure and to avoid the chemicals employed for the removal of hard templates.

Similar to the self-assembly observed during the synthesis of ordered mesoporous metal oxides, soft-templating of

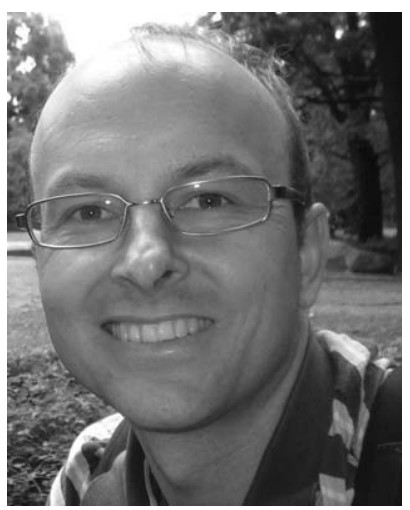

Bernd M. Smarsly
Bernd Smarsly studied chemistry and physics at the University of Marburg, Germany, and Innsbruck, Austria, and received a Masters degree of Natural Science in 1998. He completed his PhD studies in 2001 at the Max Planck Institute of Colloids and Interfaces. From 2002-2003 he worked as a postdoctoral researcher at the Advanced Materials Laboratory of the University of New Mexico at Albuquerque, USA. From 2003 to 2007 he worked as a group leader at MPI of Colloids and Interfaces. In 2007 he was appointed full professor for physical chemistry at the University of Giessen (Germany). His main research interests focus on the preparation of functional, mesostructured metal oxides and carbon, their physico-chemical properties, and the development of novel characterization techniques, especially using $X$-ray scattering. mesoporous carbon materials involves the cooperative assembly of structure-directing agents able to form lyotropic phases with suitable organic carbon precursors. Since the first successful synthesis of ordered mesoporous carbons by soft-templating with micelles of amphiphilic block-copolymers reported by Dai and co-workers in 2004, ${ }^{17}$ rapid progress in this field has been reviewed by different authors. ${ }^{12,15,18,19}$ More recently, the softtemplating approach has been extended to synthesize macropores in hierarchical meso-macroporous carbon without the help of any inorganic templating material $\left(\right.$ e.g. $\left.\mathrm{SiO}_{2}\right) .^{20-23}$ Thus, softtemplating of meso- and macropores using only organic species can now provide access routes towards chemically pure carbon with controlled hierarchical porosity.

In this review, we describe recent progress in the synthesis of mesoporous and hierarchical meso-macroporous carbon materials via soft-templating strategies. Particular attention is paid to routes using pure organic templates. The present review first provides the principles of the soft-templating of mesoporous carbons along with important examples. Thereafter, the means of controlling size and morphology of mesopores are reviewed. The role of carbon precursor, solvent and polymerization catalyst is discussed. Finally, synthesis paths for hierarchical structures are reported and selected applications are briefly summarized.

\section{Principles of soft-templating of mesoporous carbon using amphiphilic block-copolymers}

Similar to metal oxides, mesoporous carbon materials with ordered mesoporosity and narrow pore size distribution can be synthesized using a nanocasting approach that employs micelles of amphiphilic block-copolymers as templates. The most common copolymers are poly(ethylene oxide)- $b$-poly(propylene oxide)- $b$-poly(ethylene oxide) triblock-copolymers (PEO- $b$-PPO$b$-PEO) from the Pluronic family, ${ }^{24-26}$ polystyrene- $b$-poly(4vinylpiridine) $\left(\mathrm{PS}-b\right.$-P4VP) ${ }^{17}$ or polystyrene- $b$-poly(ethylene oxide) (PS- $b$-PEO). ${ }^{27}$ Typically applied carbon precursors are small clusters of phenol-formaldehyde, or so-called "resol" (a soluble low-molecular weight polymer $\left(M_{\mathrm{w}}=500-5000 \mathrm{~g} \mathrm{~mol}^{-1}\right)$ derived from acid-catalyzed or base-catalyzed polymerization of a mixture of phenol and formaldehyde), ${ }^{26-29}$ so-called "RF resin" (resorcinol-formalydehyde) ${ }^{17}$ and "PF resin" phloroglucinolformaldehyde. ${ }^{24}$ Typical synthesis procedures involve the mixing of a solvent (such as ethanol, water, THF, or mixtures of them), precursor (e.g. a resin of low molecular weight containing $\mathrm{OH}$ groups), and template (e.g. tri-block-copolymers of the type PEO- $b$-PPO- $b$-PEO). This mixture assembles into an ordered mesophase. The mesophase is stabilized via thermal or catalytic cross-linking. Finally, the template is removed, e.g. by thermal treatment, which results in a porous carbonaceous material. The thermal treatment also induces a compaction of the material, which leads to a shrinkage of the pore system. The shrinkage occurs either isotropically (powders) or uni-axially (films on a substrate), where uniaxial shrinkage perpendicular to the substrate results in elliptical deformation of the pore shape. ${ }^{30}$ The described synthesis approach provides access to mesoporous carbons with pore sizes ranging from $3-30 \mathrm{~nm},{ }^{17,28,29}$ and with surface areas between $280^{29}$ and $1510 \mathrm{~m}^{2} \mathrm{~g}^{-1}{ }^{27}$ 


\subsection{Key issues for the successful synthesis}

The synthesis of mesoporous carbons via micelle templating imposes a number of requirements on the chemical and physical material behaviour of the synthesis ingredients. ${ }^{18}$ In order to derive micelle-templated mesoporous carbon (1), the structuredirecting polymer must provide a driving force for micelle formation, and strong interaction between the precursor and one of the blocks in the templating block-copolymer, such as e.g. hydrogen-bonding between $\mathrm{PEO}$-chains in the template and $\mathrm{OH}$ groups in the precursor resin, is required to prevent macrophase separation. Furthermore, (2) the precursor should be able to cross-link in order to stabilize the framework of the forming pore system. Finally, (3) the cross-linked precursor should possess a higher thermal stability than the template in order to facilitate thermal template removal without collapse of the pore structure. The listed conditions are discussed in more detail below.

Condition 1: interactions between templates and precursors. In order to form a mesostructured phase from a structure-directing agent and precursor, a driving force must exist for microphase separation. The driving force for micelle formation and selfassembly of the structure-directing agent, usually a blockcopolymer, is based on the constituent blocks of the polymer possessing different affinities to the precursor resin, where one block interacts more strongly (e.g. through hydrogen bonding) with the precursor resins than the other block.

This can be achieved by selecting carbon precursors containing a large number of hydroxyl groups $(-\mathrm{OH}),{ }^{17,18,24}$ which can strongly interact with the polar parts of structure-directing block-copolymers. Furthermore, precursor aggregates should be small enough to enable assembly around micelles.

The most commonly employed mechanism for self-assembly is the $\mathrm{I}^{0} \mathrm{~S}^{0}$ mechanism, where I represents $-\mathrm{OH}$ or $-\mathrm{NH}$ moieties of the carbon precursors and $\mathrm{S}$ represents hydrophilic blocks of block-copolymers, respectively. ${ }^{31,32}$ This mechanism relies on hydrogen bonding between template polymer blocks and precursor resin. ${ }^{18,25,33}$ Such H-bonding resembles the formation mechanism of mesostructured oxides proposed as modulation of the hybrid interface mechanism (MHI). ${ }^{31,34}$ In general, the $I^{0} \mathrm{~S}^{0}$ mechanism involves both the neutral polymer blocks and precursor molecules in the absence of electrostatic interactions. Dai et al., however, recently reported that under highly acidic conditions the self-assembly of polymeric precursors can also be driven by $\mathrm{I}^{+} \mathrm{X}^{-} \mathrm{S}^{+}$mechanism; where $\mathrm{X}$ represents counterions $\left(\mathrm{Cl}^{-}\right.$in this case), along with the normal $\mathrm{I}^{0} \mathrm{~S}^{0}$ mechanism. ${ }^{35}$ The acidic conditions induce protonation of phenol molecules (or their derivatives) and of cross-linked phenols. Moreover, the EO blocks of the Pluronic block-copolymers are also protonated. Using $\mathrm{Cl}^{-}$as a mediator, coulombic interactions can then facilitate the $\mathrm{I}^{+} \mathrm{X}^{-} \mathrm{S}^{+}$mechanism and enable the self-assembly of surfactant-polymer nanocomposites. ${ }^{35}$ Very recently, Goldfarb et al. reported on formation mechanism of a cubic mesoporous carbon monolith synthesized using the resol and F127 as a precursor and template through the EISA process using electron paramagnetic resonance (EPR). ${ }^{36}$ The investigation demonstrated that during evaporation, a resol-pluronic composite is formed through strong $\mathrm{H}$-bonds between hydroxyl groups of the resol and oxygens of the PEO block, with the resol penetrating all the way to the PPO-PEO interface. During the thermopolymerization step, the $\mathrm{PPO}-\mathrm{PEO}$ regions are segregated more strongly, while the polymerizing resol is driven out to the outer PEO corona, resulting in an ordered composite with a resol-free PPO core.

Condition 2: ability of precursors to cross-link. In order to provide a sufficiently stable and rigid framework that withstands template removal, which is typically carried out at temperatures between $350^{28,29}$ and $1800{ }^{\circ} \mathrm{C},{ }^{35}$ carbon precursors must undergo a stabilization process prior to the template removal. This stabilization can be achieved by "thermal curing" in either basecatalyzed or acid-catalyzed condensation of the typically employed precursor combination of resol or phenol and formaldehyde. ${ }^{18,35}$ In cases where precursor molecules lack 3-D interconnecting sites, such as linear novolac resins, insufficient cross-linking results in unstable frameworks, which are prone to pore collapse upon carbonization. ${ }^{37,38}$

Condition 3: different thermal stability between precursors and templates. Removal of the template is a key step for obtaining mesoporous carbon structures. Template removal is usually realized by thermal treatment ("carbonization") under inert gas atmosphere that relies on the difference in thermal stability between the template and the carbon precursors. According to thermogravimetric analysis (TGA) under inert atmosphere $\left(\mathrm{N}_{2}\right.$ or Ar), notable weight losses of approximately 97.5, 98.8, and $96.8 \%$ are observed in the temperature range of $300-400{ }^{\circ} \mathrm{C}$ for pure template copolymers F127, P123, and F108, respectively, ${ }^{29}$ while PS- $b$-P4VP starts to decompose at $328{ }^{\circ} \mathrm{C}$ and finishes at $430{ }^{\circ} \mathrm{C}$ with only negligible residue $(0.7 \mathrm{wt} \%) .{ }^{17}$ In contrast, common resins (resol, resorcinol-formaldehyde) release under inert atmosphere only small molecules at such temperatures, i.e. water, $\mathrm{H}_{2}, \mathrm{CO}_{2}$, but retain the cross-linked precursor framework. $^{12}$ Employing an inert atmosphere $\left(\mathrm{N}_{2}\right.$, Ar) prevents combustion of the carbon precursor.

Besides being stable enough to withstand template removal, the precursors must also be able to transform into a carbon matrix during subsequent treatments at higher temperatures. In general, properties such as electrical conductivity, adsorption and catalytic functionality largely depend on the extent to which the carbonized material is transformed into graphite.

Temperatures reported for thermal treatment range from $350^{28,29}$ to $2600{ }^{\circ} \mathrm{C} .{ }^{35}$ In general, a temperature of at least $600{ }^{\circ} \mathrm{C}$ is required to completely carbonize the precursor matrix, hence materials treated at lower temperatures do not possess a fully carbonized framework. ${ }^{29}$

Unfortunately, excessive temperatures induce a collapse of the carbon mesopores. Hence, a complete conversion of the mesoporous carbon framework has not been reported so far.

A critical view on the carbon microstructure. With respect to the carbonization of such resins, it is important to discuss the impact of the heat treatment on the microstructure of carbonaceous materials with $\mathrm{sp}^{2}$ carbon as the predominant hybridization. In numerous publications, the terms "graphitization" and "graphitic carbon" are used for the aforementioned resin-derived carbons, which is, however, not applicable to the materials presented. Strictly speaking, "graphitic carbon" is a well-defined 
term: "The use of the term graphitic carbon is justified if threedimensional hexagonal crystalline long-range order can be detected in the material by diffraction methods, independent of the volume fraction and the homogeneity of distribution of such crystalline domains. Otherwise, the term "non-graphitic carbon" should be used." ${ }^{39}$ Thus, "non-graphitic carbon" is the correct term to describe $\mathrm{sp}^{2}$ carbon materials showing diffuse reflections in XRD experiments without the presence of $(h k l)$ reflections. This corresponds to graphene stacks without 3D correlation between the stacked graphenes. The quite diffuse reflections observed in X-ray scattering of templated carbons result from the significant degree of disorder and the small size of the graphene stacks. ${ }^{40}$ Hence, a classification of resin-based carbons as "graphitic" is obsolete, unless 3D long-range order can be shown by XRD experiments; such XRD patterns, to the best of our knowledge, are not observed for soft-templated carbons, taking into account that "graphitization" usually occurs at temperatures above $c a .2200{ }^{\circ} \mathrm{C}$ at minimum, where the mesostructure usually breaks down. ${ }^{35}$ The microstructure of such "nongraphitic" carbons and the evaluation by appropriate X-ray scattering approaches is described in the literature. ${ }^{40-42}$

\subsection{Typical examples for the synthesis of micelle-templated mesoporous carbon}

Different synthesis routes allow the preparation of mesoporous carbons with different pore structures such as two-dimensional hexagonal $(p 6 \mathrm{~mm})$, three-dimensional bicontinuous $(\mathrm{Ia} 3 \mathrm{~d})$, or body-centered cubic $(\operatorname{Im} 3 m)$. In 2004, Dai and co-workers established the synthesis of crack-free highly ordered hexagonal mesoporous carbon films via soft-templating using PS- $b$-P4VP as a template, resorcinol as carbon precursors, and formaldehyde to induce polymerization of the resorcinol molecules. ${ }^{17}$ The reported synthesis procedure is illustrated in Fig. 1a. It involves formation of the molecular assembly, film casting, control of the solvent evaporation, polymerization of the resorcinol located in-between $\mathrm{P} 4 \mathrm{VP}$ regions using gaseous formaldehyde, and finally thermal treatment at $800{ }^{\circ} \mathrm{C}$ to remove the polymer template and form a carbon matrix. SEM images of the resulting material are depicted in Fig. $1 \mathrm{~b}$ and $\mathrm{c}$, showing thin films ( $c a .100 \mathrm{~nm})$ completely penetrated by a hexagonal pore arrangement.

Ikkala et al. reported the formation of ordered mesoporous polymers utilizing also PS- $b$-P4VP, but a different precursor, phenolic resin. Pore structures were varied between worm-like, spherical and lamellar structures by adjusting the ratio of phenolic resin to the amount of template. Samples in the shape of films with thicknesses up to about 100 micrometers were synthesized. However, calcination was performed only at $420^{\circ} \mathrm{C}$, a temperature which is sufficient for template removal, but not for carbonization. ${ }^{38,43}$

Due to pricing and availability, the template polymer PS- $b$ P4VS is probably not suitable for a large-scale synthesis. Tanaka et al. demonstrated that the common and cheap Pluronic triblock-copolymer PEO- $b$-PPO- $b$-PEO can also template mesoporous carbon. ${ }^{44}$ They employed Pluronic F127 as a template, resorcinol-formaldehyde "RF" as a carbon precursor, and triethyl orthoacetate (EOA) as a co-precursor. EOA served two purposes; it increased the carbon content of the final material and significantly enhanced the ordering of the porous structures. As shown in Fig. 2, films with hexagonally ordered pores arranged parallel to the substrate are obtained after spin coating of the solutions, curing at $90^{\circ} \mathrm{C}$ and subsequent carbonization at temperatures ranging from 400 to $800{ }^{\circ} \mathrm{C}$.

Zhao et al. demonstrated that also other polymers from the Pluronic family act as templates in the synthesis of mesoporous carbons from resol ${ }^{18}$ i.e. F127, ${ }^{28,29} \mathrm{~F} 108^{29}$ as well as $\mathrm{P} 123 .^{25,28}$ The formed pore structure can be tuned by variation of the fraction of the hydrophobic block, either via the PEO content of the blockcopolymer or via changing the resol-to-template ratio in the solution. The resulting increase in curvature at the micelle interface in the composite provides the incentive for mesophase transition from lamellar $(L a)$ towards bicontinuous $(I a 3 d)$, hexagonal $(p 6 \mathrm{~mm})$, and cubic globular $(\operatorname{Im} 3 \mathrm{~m})$, as illustrated in Fig. 3.

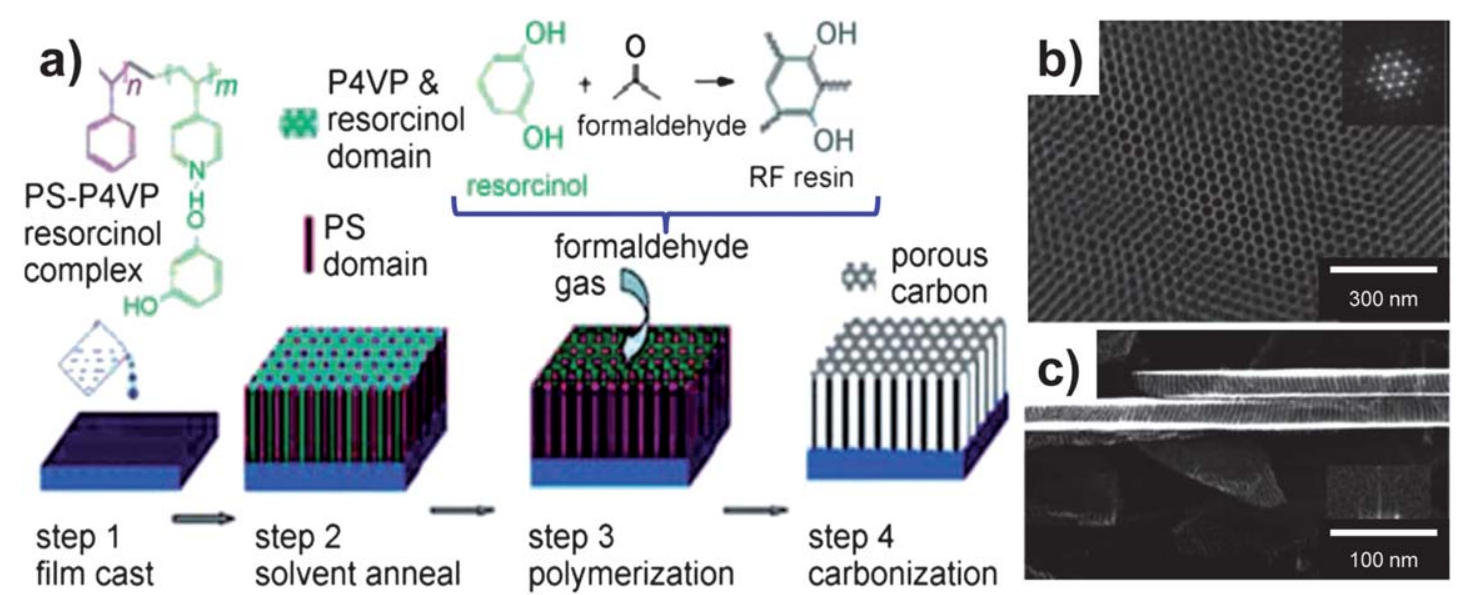

Fig. 1 Synthesis of mesoporous carbon templated with micelles of PS- $b$-P4VP as reported by Dai et al. ${ }^{17}$ (a) schematic representation of the synthesis process. Step 1: film casting of PS- $b$-P4VP/resorcinol supramolecular assembly on Si wafer. Step 2: microphase separation during solvent annealing at $80^{\circ} \mathrm{C}$ in DMF-benzene vapour. Resorcinol organizes between the P4VP domains. Step 3: polymerization of resorcinol exposing the film to formaldehyde gas. Step 4: pyrolysis in $\mathrm{N}_{2}$ resulting in arrays of hexagonally arranged carbon channels. (b) SEM image after carbonization at $800{ }^{\circ} \mathrm{C}$ (top view). (c) SEM image in cross section, showing pore channels perpendicular to the substrate surface. Reproduced with permission from ref. 17. 

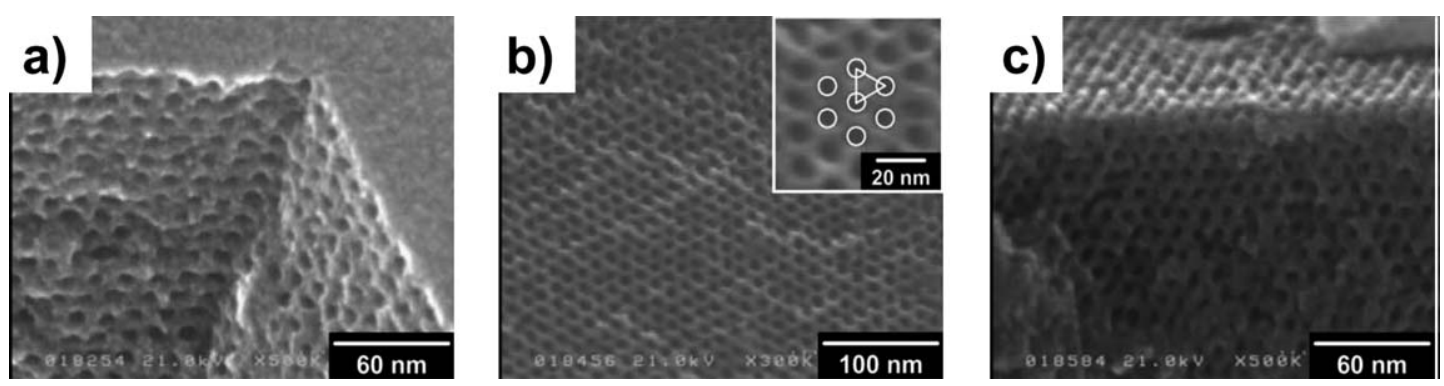

Fig. 2 Mesoporous carbon synthesized by Tanaka et al. ${ }^{44}$ from mixtures of resorcinol-formaldehyde, triethyl orthoacetate and Pluronic F127. SEM images of the carbon materials after calcination at temperatures of (a) $400{ }^{\circ} \mathrm{C}$, (b) $600{ }^{\circ} \mathrm{C}$ and (c) $800{ }^{\circ} \mathrm{C}$. Reproduced with permission from ref. 44 . Copyright 2005, The Royal Society of Chemistry.

\section{Control over pore morphology, pore size and approaches to obtain large mesopores}

\subsection{Templating with conventional pluronic polymers}

Significant effort has been dedicated to elucidating factors that control the morphology and pore size of templated mesoporous carbons, including different templates such as Pluronic F127 and P123 and different carbon precursors. Besides the ratio between the amounts of precursor and template various other synthesis parameters also affect the final pore morphology of mesoporous carbons. ${ }^{45-53}$ Tanaka et al. ${ }^{46}$ demonstrated the importance of the solution composition: carbon powders were synthesized from resorcinol-phloroglucinol/formaldehyde and F127 dissolved in different amounts of ethanol and water. A three dimensional wormhole-like mesostructure was formed with $\mathrm{EtOH} /$ water ratios in the range of 0.5 to 1.25 . When the molar ratio was increased to 2.5 , a hexagonal $p 6 \mathrm{~mm}$ structure was obtained. This observation was explained by the fact that ethanol swells the hydrophobic cores of F127 micelles and interacts with both PPO and PEO segments due to its polar characteristics. Hence, ethanol molecules are located at the hydrophilic-hydrophobic interface, which results in a decreased interfacial curvature and in consequence induces a transition between different phases of the micelle-templated pore system as a function of water and ethanol content.

Long et al. synthesized mesoporous carbons using resorcinolfurfural oligomers as a precursor and F127 as a template. ${ }^{45}$ They reported that at the same ratio between amounts of precursor and template an increase in the degree of polymerization of the precursor resin induced a mesophase transition from $\operatorname{Im} 3 m$ to p6mm and then to a disordered phase. The degree of polymerization was adjusted using different reaction times of precursor cross-linking. The observed phase transition was attributed to the lower thermodynamic driving force of oligomers to mix with PEO segments. In a similar study, Hayashi et al. recently reported that the pore diameter of soft-templated mesoporous carbons also changes with polymerization time. ${ }^{54}$ They used resorcinol-formaldehyde, triethyl orthoacetate (EOA) and F127

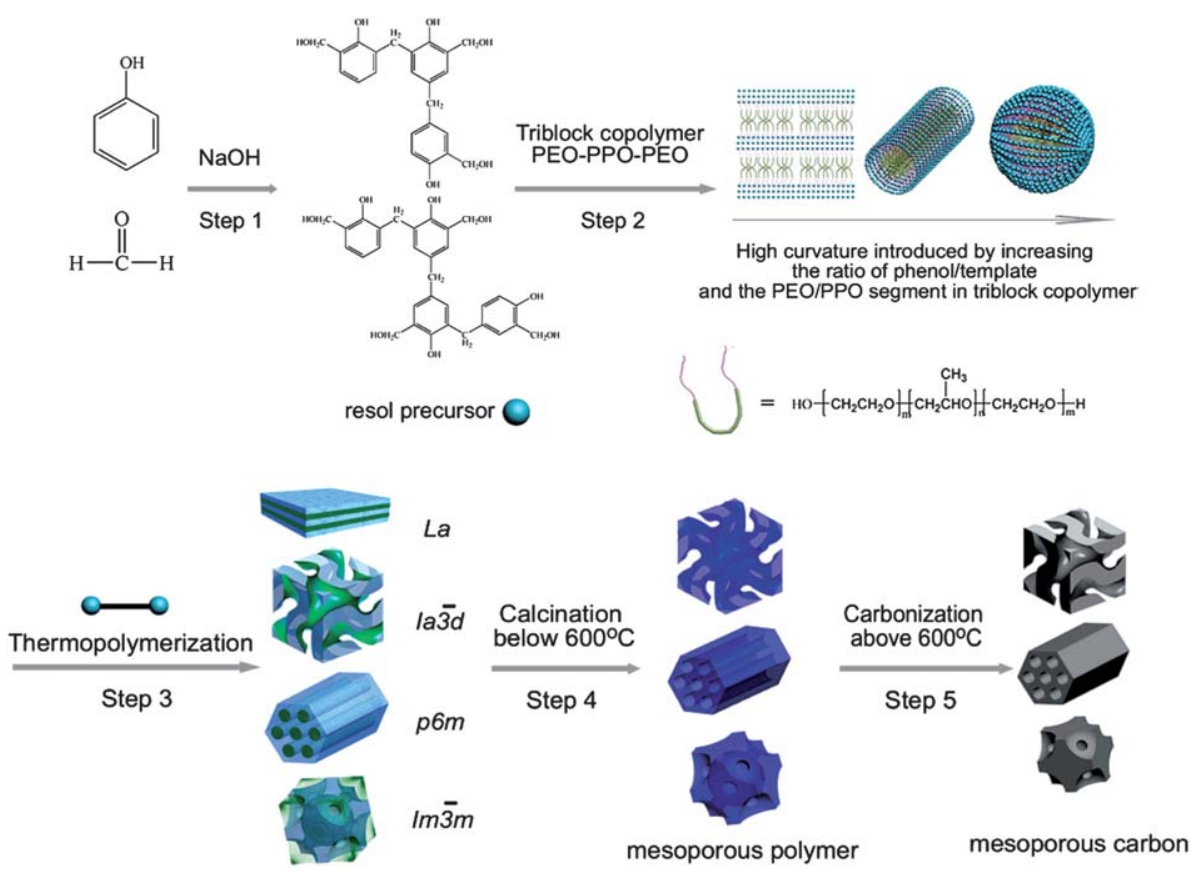

Fig. 3 Schematic illustration of the preparation of ordered mesoporous polymer resins and carbon frameworks using resol as a carbon precursor as reported by Zhao et al. ${ }^{29}$ The obtained pore structure can be controlled in step 2 by the composition and concentration of the template polymer. Reproduced with permission from ref. 29. Copyright 2006, American Chemical Society. 
as a precursor, co-precursor and template, respectively, under acidic conditions. Extending polymerization time while keeping other parameters constant, they enlarged pore sizes from 7 to $12.5 \mathrm{~nm}$. The increase in pore size was rationalized by the expansion of the micelle core of F127 due to higher water content that was incorporated into the micelle core.

The mesostructure of mesoporous carbons can also be adjusted using mixtures of different template molecules. This approach has been illustrated by Qian et al. ${ }^{53}$ They used resol as a carbon precursor and ethanol as a solvent in combination with different mixtures of Pluronic type polymers of regular (e.g. $\left.\mathrm{F} 127: \mathrm{PEO}_{100}-b-\mathrm{PPO}_{70}-b-\mathrm{PEO}_{100}\right)$ as well as inverse structure $\left(\mathrm{PPO}_{19}-b-\mathrm{PEO}_{33}-b-\mathrm{PPO}_{19}\right)$. A simple estimation of the molar ratio of hydrophilic and hydrophobic sections was proposed to predict the final mesostructure of the resulting mesoporous carbons. By changing the molar ratio of $\mathrm{F} 127$ to $\mathrm{PEO}_{19}-b$ $\mathrm{PEO}_{33}-b-\mathrm{PPO}_{19}$, two different phases were obtained, i.e. $p 6 \mathrm{~mm}$ and $\operatorname{Im} 3 m$.

\subsection{Towards bigger mesopore size with larger polymers and swelling agents}

Size and connectivity of pores are important criteria for many practical applications. Different Pluronic polymers can template cubic pore systems with pore diameters between $3 \mathrm{~nm}^{25,29,55}$ and 7 $\mathrm{nm} .{ }^{26,56}$ Using high-molecular-weight PS- $b$-P4VP as a template and resorcinol-formaldehyde as a precursor, Dai et al. synthesized mesoporous carbon films possessing larger pores of around $33 \mathrm{~nm}$ in diameter, yet pores were hexagonally arranged parallel to the substrate, i.e. not well interconnected. ${ }^{17}$ To accomplish the synthesis of carbon materials with large mesopores also in cubic pore systems, two different approaches have been pursued: increasing the size of template molecules to generate larger micelles, and swelling of the micelles by addition of an additional swelling agent.

Zhao et al. employed high-molecular-weight PS- $b$-PEO polymers with various sizes of the PS block. ${ }^{27,57}$ The templates PS- $b$-PEO were synthesized through atom transfer radical polymerization (ATRP). By controlling the polymerization time, polymers with different PS block lengths were obtained. Average molecular weights of the polymers amounted to 17900,29700 , and 37200 , corresponding to approximate molecular compositions of $\mathrm{PS}_{120}-b-\mathrm{PEO}_{125}, \mathrm{PS}_{230}-b-\mathrm{PEO}_{125}$ and $\mathrm{PS}_{305}-b-\mathrm{PEO}_{125}$, respectively. Mesoporous carbon films were then synthesized using the template polymers in combination with THF as a solvent and resol as a carbon precursor. SAXS and TEM analysis indicated formation of mesostructured carbon of fcc type with a space group $F m 3 m$. Mesopores templated by $\mathrm{PS}_{120}-b-\mathrm{PEO}_{125}$, $\mathrm{PS}_{230}-b-\mathrm{PEO}_{125}$ and $\mathrm{PS}_{305}-b-\mathrm{PEO}_{125}$ measured $11.9,22.7$ and $33.3 \mathrm{~nm}$ in diameter and featured cell parameters of 33.0, 46.5 and $54.2 \mathrm{~nm}$, respectively. A SEM image of the carbon with pores templated with $\mathrm{PS}_{230}-b$-PEO $\mathrm{PE}_{125}$ is shown in Fig. $4 \mathrm{a}$.

Besides two-component block-copolymers of AB type (e.g. PS$b$-PEO) and ABA type (e.g. PEO- $b$-PPO- $b$-PEO) also triblockcopolymers of $\mathrm{ABC}$ type have been developed, featuring not only higher molecular weights, but also graded functionality along the molecule chains. Zhao et al. synthesized an amphiphilic ABC-type triblock-copolymer $\left(\mathrm{PEO}_{125}-b\right.$ - $\left.\mathrm{PMMA}_{100}-b-\mathrm{PS}_{138}\right)$ with gradient hydrophilicity using ATRP method. The polymer templates highly ordered mesoporous carbons with pore diameters up to $20 \mathrm{~nm}$ using resol as a carbon precursor and THF as a solvent. ${ }^{58}$ The carbon films obtained via evaporation-induced self-assembly (EISA) featured a face-centered cubic (fcc) closedpacked mesostructure (space group Fm $3 m$ ) (see Fig. 4b). Yet, the tailored synthesis of one ABC-type polymer for each pore size requires significant effort.

In contrast, changing the size of a micelle by swelling its core with a swelling agent as reported e.g. for the synthesis of mesoporous silica ${ }^{32,59-62}$ is a more facile and flexible method of pore size tuning. Zhao et al. synthesized ultra-large-pore ordered mesoporous carbons employing a diblock-copolymer $\mathrm{PS}_{230}-b$ $\mathrm{PEO}_{125}$ as a template and low-molecular-weight homopolystyrene $\left(M_{\mathrm{n}}\right.$ of $\left.5100 \mathrm{~g} \mathrm{~mol}^{-1}, \mathrm{~h}-\mathrm{PS}_{49}\right)$ as a "pore expander" using resol as a carbon precursor and THF as a solvent. ${ }^{63}$ EISA was employed for film casting. Samples were carbonized in flowing $\mathrm{N}_{2}$ at $800{ }^{\circ} \mathrm{C}$. When the amount of swelling agent h-PS was varied between 0 and $20 \mathrm{wt} \%$ relative to PS- $b$-PEO content, mesoporous carbons with highly ordered face-centre cubic mesostructure (space group $F m 3 m$ ) were obtained. The pore size was tuned in the range of 23 to $37 \mathrm{~nm}$, and corresponding cell
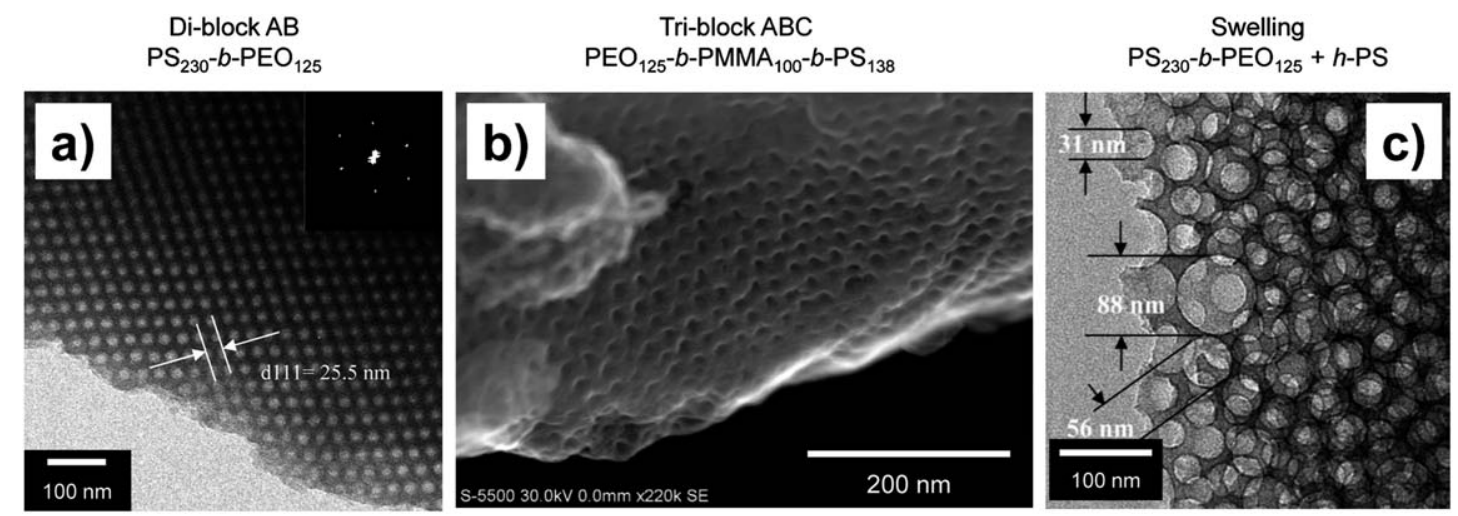

Fig. 4 Carbon materials with large mesopores derived by different approaches: (a) TEM image of mesoporous carbon templated by Zhao et al. ${ }^{27}$ with di-block copolymer $\mathrm{PS}_{230}-b$ - $\mathrm{PEO}_{125}$ after carbonization in $\mathrm{N}_{2}$ at $800^{\circ} \mathrm{C}$. (b) SEM image of mesoporous carbon templated by Schüth and Zhao et al. ${ }^{58}$ using ABC type triblock $\mathrm{PEO}_{125}-b$-PMMA $\mathrm{PM}_{100}-b$ - $\mathrm{PS}_{138}$ after carbonization in $\mathrm{N}_{2}$ at $1200^{\circ} \mathrm{C}$. (c) TEM image of an ultra-large mesopore carbon prepared by Zhao et al. ${ }^{63}$ adding $30 \mathrm{wt} \%$ of pore-swelling agent h-PS to solutions containing micelles of $\mathrm{PS}_{230}-b-\mathrm{PEO}_{125}$ as a template. The sample was carbonized in $\mathrm{N}_{2}$ at $800^{\circ} \mathrm{C}$. Reproduced with permission from ref. 27,58 and 63, respectively. Copyright 2007, 2008, 2009, American Chemical Society. 
parameters amounted to 46 to $58 \mathrm{~nm}$. However, with increasing amount of h-PS the wall thickness decreased from 9.9 down to $3.6 \mathrm{~nm}$. Moreover, a further increase in h-PS content resulted in larger pore sizes up to $90 \mathrm{~nm}$, but also in multimodal pore size distributions and the formation of a foam-like disordered porous structure (Fig. 4c).

Mechanistically, the increase in pore size upon h-PS addition has been explained by a continuous solubilizing process. Whereas the PEO block of PS- $b$-PEO interacts with the resol resin, the PS block forms the micelle core. Due to its small size and hydrophobic nature the swelling agent h-PS is soluble in the micelle core and increases the core size. In contrast, an excessive amount of h-PS added to the system cannot be homogeneously accommodated in the micelle cores, resulting in simultaneous microphase and macrophase separation and the formation of a worm-like disordered mesostructure. Hence, excessive swelling of micelles to generate ultra-large mesopores gradually compromises order and homogeneity of the templated pore system.

\section{Roles of the carbon precursors, solvents and catalysts}

The choice of precursor is critical to the formation of mesoporous carbons. Precursor molecules typically employed in the resin formation that precedes the synthesis of soft-templated mesoporous carbons are shown in Fig. 5, i.e. phenol, resorcinol, and phloroglucinol. Chemical cross-linking of these molecules, often with formaldehyde acting as a linker, forms the oligomers that co-assemble with the template micelles. Due to a high degree of cross-linking that can be obtained by a simple thermal
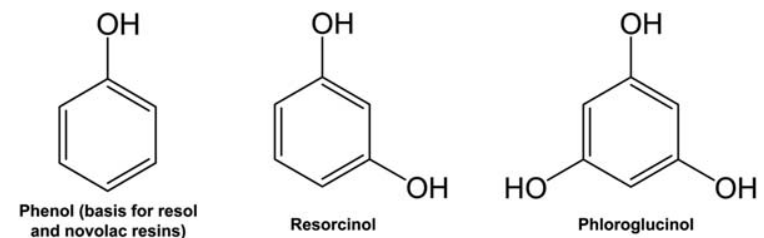

Fig. 5 Chemical structures of precursor molecules that are commonly used in the preparation of the precursor resin used for soft-templating of mesoporous carbon materials. treatment around $100{ }^{\circ} \mathrm{C}$, resol is the most common choice of precursor resin. The resol precursor resin consists of low molecular-weight clusters of phenol units that are linked mainly through methylene groups. It is produced by acid-catalyzed or base-catalyzed polymerization of phenol and formaldehyde employing a molar formaldehyde-to-phenol ratio greater than one. After neutralization, the hydroxyl groups of resol facilitate hydrogen bonding with hydrophilic chains of block-copolymers inducing the desired microphase separation. ${ }^{18,28,36,56,58,64}$

Novolac is also a phenol-formaldehyde resin, but synthesized at a formaldehyde-to-phenol ratio less than one. Since a molar ratio formaldehyde to phenol of one enables every phenol to be linked via methylene bridges, in theory one single cross-linked molecule results. Thus, Novolac resins are less suitable than resol resins to generate a framework that withstands thermal template removal due to their lower degree of cross-linking. ${ }^{43,55}$

Other precursor resins that have been employed for the synthesis of mesoporous carbon are based on either resorcinol or phloroglucinol. The structural similarity to phenol evident from Fig. 5 implies similarities also in chemistry and polymerization behaviour, but gradual differences in terms of interaction strength with the template polymer and the degree of crosslinking. Dai et al. reported that phloroglucinol (1,3,5-trihydroxybenzene) interacts more strongly than phenol-formaldehyde or resorcinol-formaldehyde complexes with Pluronic templates due to the fact that it can form triple hydrogen bonds with the PEO blocks of F127. ${ }^{24}$ The proposed mechanism of interaction between phloroglucinol and Pluronic-type templates is illustrated in Fig. 6. Moreover, phloroglucinol was reported to polymerize more rapidly than either resorcinol or phenol (about 40 min vs. 1 and 2 to 3 weeks, respectively, for mixtures with formaldehyde, ethanol, water, F127 and $0.01 \mathrm{M} \mathrm{HCl}$ ). In addition, the structure of mesoporous carbon obtained under similar synthesis conditions (curing at $100{ }^{\circ} \mathrm{C}$, carbonization at $850{ }^{\circ} \mathrm{C}$ under nitrogen atmosphere), but with the different precursors, differed significantly. ${ }^{24}$ Whereas carbons based on phloroglucinol possessed a highly ordered 2-D hexagonal system $(p 6 \mathrm{~mm})$, resorcinol and phenol only resulted in poorly structured microporous carbons. Hence, the $\mathrm{OH}$ content of the precursor molecule as well as the formaldehyde content in the resin are variables that can be used to adjust the self-assembly behaviour and thermal stability of the structured mesophase.
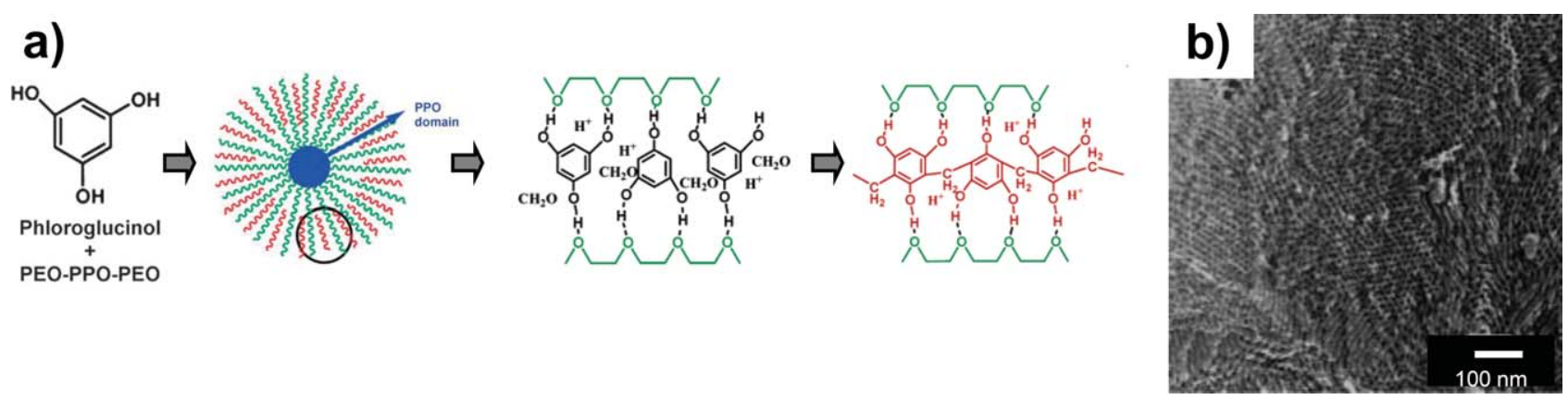

Fig. 6 Synthesis of mesoporous carbon from an alternative precursor, phloroglucinol as reported by Dai and co-workers. ${ }^{24}$ (a) Schematic illustration of polymerization of phloroglucinol and formaldehyde and its interaction with PPO block of micelles of the template polymer. (b) SEM image of the mesoporous carbon obtained by templating with F127 and calcination at $850^{\circ} \mathrm{C}$. Reproduced with permission from ref. 24. Copyright 2006 , American Chemical Society. 
The synthesis approaches described so far employ organic solvents such as ethanol, THF, or their mixtures with water. In contrast, Lu and Schüth et al. reported the synthesis of mesoporous carbons in an aqueous phase under mild conditions. ${ }^{65} \mathrm{In}$ the synthesis procedure, cross-linking of the precursor resin resorcinol-formaldehyde was catalyzed by an amino acid (glutamic acid) whereas Pluronic F127 served as a structure-directing agent. Phase separation occurred within $10 \mathrm{~h}$ at $60^{\circ} \mathrm{C}$, which was accelerated at higher reaction temperatures. After further aging at $90{ }^{\circ} \mathrm{C}$ for $48 \mathrm{~h}$ the obtained precipitate, a glass-like bright red solid, was converted into mesoporous carbon by carbonization under an argon atmosphere at a temperature up to $850{ }^{\circ} \mathrm{C}$.

The idea of using halogen-free cross-linking catalysts was further pursued by the same group. ${ }^{66,67} \mathrm{~N}$-containing catalysts, namely 1,6-diaminohexane (DAH) ${ }^{66}$ and lysine, ${ }^{67}$ were used in a synthesis that involved resorcinol and formaldehyde as a carbon precursor and F127 as a template. Using either catalyst in the polymerization of resorcinol and formaldehyde resulted in rapid gelation within $15 \mathrm{~min}$ at $90^{\circ} \mathrm{C}$. The polymer monoliths thus obtained were dried and then carbonized at $800-850{ }^{\circ} \mathrm{C}$ under nitrogen, which yielded crack-free mesoporous carbon monoliths. More interestingly, the synthesis resulted in a nitrogencontaining framework of the carbon monoliths, where the nitrogen contained in the DAH or lysine catalysts was incorporated into the final carbon structure. Since only hydrocarbon molecules are present in the reaction systems, i.e. no metal or halogenide ions, the resulting carbons were of superior purity, which is beneficial to sensitive applications.

Mesoporous carbon materials can also be synthesized using renewable materials such as sugars as precursors. ${ }^{68,69}$ Antonietti et al. recently reported the synthesis of ordered mesoporous carbons through a sugar-based direct hydrothermal carbonization (HTC)/soft-templating approach. ${ }^{68}$ D-Fructose functioned as a carbon precursor whereas Pluronic F127 acted as a pore template during the synthesis under hydrothermal conditions at $130{ }^{\circ} \mathrm{C}$. Water was employed as a solvent. The mesostructured solid resulting from the hydrothermal carbonization was further carbonized by thermal treatment at $550{ }^{\circ} \mathrm{C}$ to obtain a higher carbon content. The proposed templating mechanism involves $\mathrm{H}$-bonding of D-fructose to the template PEO moiety under hydrothermal conditions.

\section{Routes to hierarchical macro- and mesoporous carbons through soft-templating}

Applications that require facile access to the internal surface of porous carbon can benefit from macropores being present in addition to mesopores. The synthesis of such hierarchical mesomacroporous materials can also be achieved employing softtemplating routes. It usually involves nanocasting of mesopores via micelle-forming template polymers in combination with mechanisms that generate the additional macroporosity. Similar to the synthesis of macroporous metal oxides, respective mechanisms employ either macropore-templating with polymer latex or a phase separation on the length scale of macropores (macrophase separation). When macrophase separation is employed, it is chemically induced via polymerization of the precursor.

\subsection{Dual templating with colloidal crystals of polymer latex and block-copolymer micelles}

Templating with a combination of polymer latex and blockcopolymer micelles was pioneered by Stein et al. who synthesized hierarchical polymer and carbon monoliths with both ordered macro- and mesopores. ${ }^{70}$ As depicted in Fig. 7a, the "dual-templating" procedure involves the infiltration of colloidal crystals of PMMA spheres (the macropore templates) with an ethanolic solution of resol and $\mathrm{HCl}$ as well as commercial block-copolymers (P123 or F127) acting as mesopore templates. By thermal curing of the resin first at $100{ }^{\circ} \mathrm{C}$, followed by heating to $140{ }^{\circ} \mathrm{C}$ under vacuum, the solvent is removed and the polymer matrix completely cross-linked. Thereafter, calcination at $450{ }^{\circ} \mathrm{C}$ decomposes the templates and produces polymer monoliths, whereas treatment at $900{ }^{\circ} \mathrm{C}$ converts them into carbon (see TEM image in Fig. 7b).
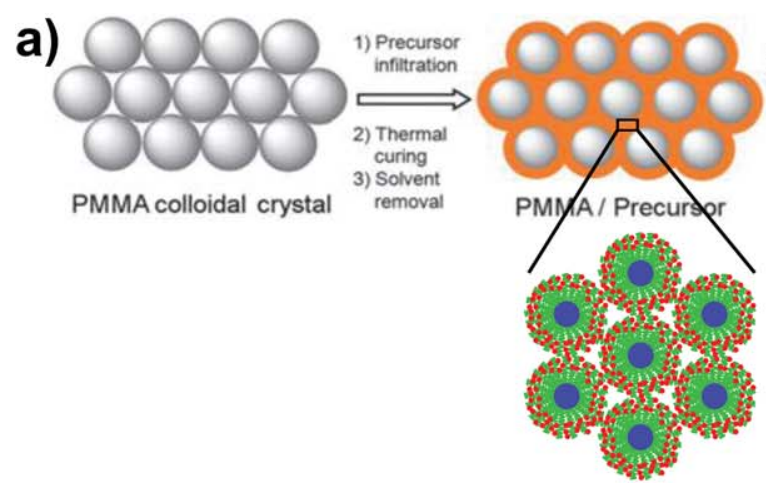

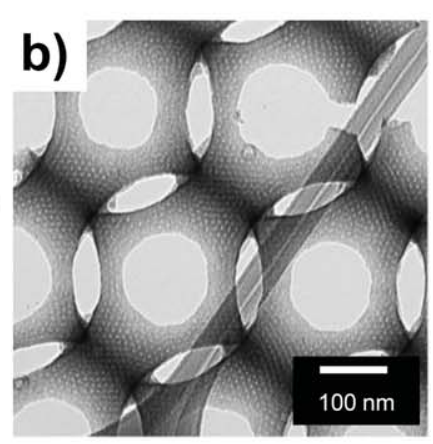

Fig. 7 Synthesis of hierarchical meso-macroporous carbon by dual templating as reported by Stein et al. $^{70}$ (a) Scheme for formation of 3DOM/m PF (phenol-formaldehyde resin) and 3DOM/m C (carbon) monoliths. The synthesis involves four basic steps: (1) infiltration of a precursor solution containing resol solution, copolymer surfactant and hydrochloric acid into a PMMA colloidal crystal template, (2) thermal cross-linking of the resol with surfactant micelles within the voids of the colloidal crystal, (3) removal of the solvent under dynamic vacuum, (4) thermal removal of the template and carbonization of the composite under an inert atmosphere. (b) TEM image of the carbon monolith $3 \mathrm{DOM} / \mathrm{m}$-cC after carbonization at $900{ }^{\circ} \mathrm{C}$. The TEM image confirms the hierarchical morphology of the sample. Reproduced with permission from ref. 70. Copyright 2008, The Royal Society of Chemistry. 
The confinement effect exerted by the colloidal crystal template, i.e. its local curvature, influences the alignment of the block-copolymer micelles. Both spherical (3DOM/m-c) and cylindrical (3DOM $/ \mathrm{m}-\mathrm{h}$ ) mesopores were observed to align parallel to the surface of PMMA spheres; hence a mesopore structure can be tuned by the size of the polymer spheres. While the reported dual-templating approach affords a highly controlled mesoporous structure and offers many different material shapes (i.e. powder, monoliths), the synthesis procedure is rather complex.

\subsection{Phase separation process combined with mesopore templates}

In contrast to latex templating, macropores can also be obtained by induced phase separation as demonstrated by Zhao et al. for hierarchical macro- and mesoporous carbon monoliths ${ }^{71}$ Similar to the synthesis procedure for mesoporous carbons, ${ }^{25}$ materials were prepared from a mixture of phenol-formaldehyde acting as a carbon precursor and $\mathrm{NaOH}$ as a catalyst, employing a mixture of P123 and F127 as the mesopore template. As in the Nakanishi process for the synthesis of macroporous silica, ${ }^{72,73}$ polymerization under hydrothermal conditions induces the separation of a phenolic resin/PEO- $b$-PPO- $b$-PEO-rich-phase and a water-rich phase under suitable conditions. The resin domains aggregate and further polymerize to form a rigid co-continuous structure, hence both the resin and aqueous phases are continuous and highly interconnected. As evidenced from SEM and TEM images shown in Fig. 8a and b, the resulting carbon possesses ordered mesopores as well as disordered bicontinuous macropores, which are built out of interconnected particles. Generally speaking, the domains of the aqueous phase act as the macropore template.
Hence, no porogen besides the block-copolymer is needed, and hierarchical macro- and mesoporous carbons with high mechanical stability can be obtained.

In parallel to the work published by Zhao, Dai et al. reported that macropores skeletons can also form via spinodal decomposition when phase separation is induced. ${ }^{74}$ Phloroglucinolformaldehyde (precursor) and F127 (mesopore template) were dissolved in a mixture of ethanol and water under acidic conditions and underwent a prepolymerization for 30 to $90 \mathrm{~min}$. The resulting polymer phase was then separated from the solvent, redissolved in glycolic solvents (ethylene glycol, diethylene glycol, triethylene glycol or tetraethylene glycol) and transferred into glass tubes. The tubes were heated to further polymerize the $\mathrm{PF}$ and induce phase separation. Fig. 8c and d show SEM and TEM images of the materials after subsequent carbonization at $850{ }^{\circ} \mathrm{C}$. The spinodal decomposition caused by chemically induced phase separation (due to ongoing polymerization) generates bicontinuous macroporous structures, which contain mesopores in the macropore walls resulting from nanocasting with F127 micelles. ${ }^{74}$ Fig. 8e illustrates the mechanistic scheme developed by Dai et al. that describes the formation of both mesopores and macropores. The resulting materials provide both high surface areas (up to $350 \mathrm{~m}^{2} \mathrm{~g}^{-1}$ ) and large pore volumes $\left(0.45 \mathrm{~cm}^{3} \mathrm{~g}^{-1}\right)$. Moreover, the carbon materials can be further heated at $2600{ }^{\circ} \mathrm{C}$ without a significant change in pore size. ${ }^{74}$

Mayes et al. reported a different synthesis route that generated hierarchical macro- and mesoporous carbons without macropore templates. They replaced formaldehyde with glyoxal $\left(\mathrm{C}_{2} \mathrm{H}_{2} \mathrm{O}_{2}\right)$. Hence, glyoxal, phloroglucinol and F127 were mixed in a mixture of ethanol and water, cross-linked at $100{ }^{\circ} \mathrm{C}$ and then calcined at $850{ }^{\circ} \mathrm{C} .{ }^{75}$ Ordered mesoporous carbons with macropores of an average size of $200 \mathrm{~nm}$ were derived, featuring also
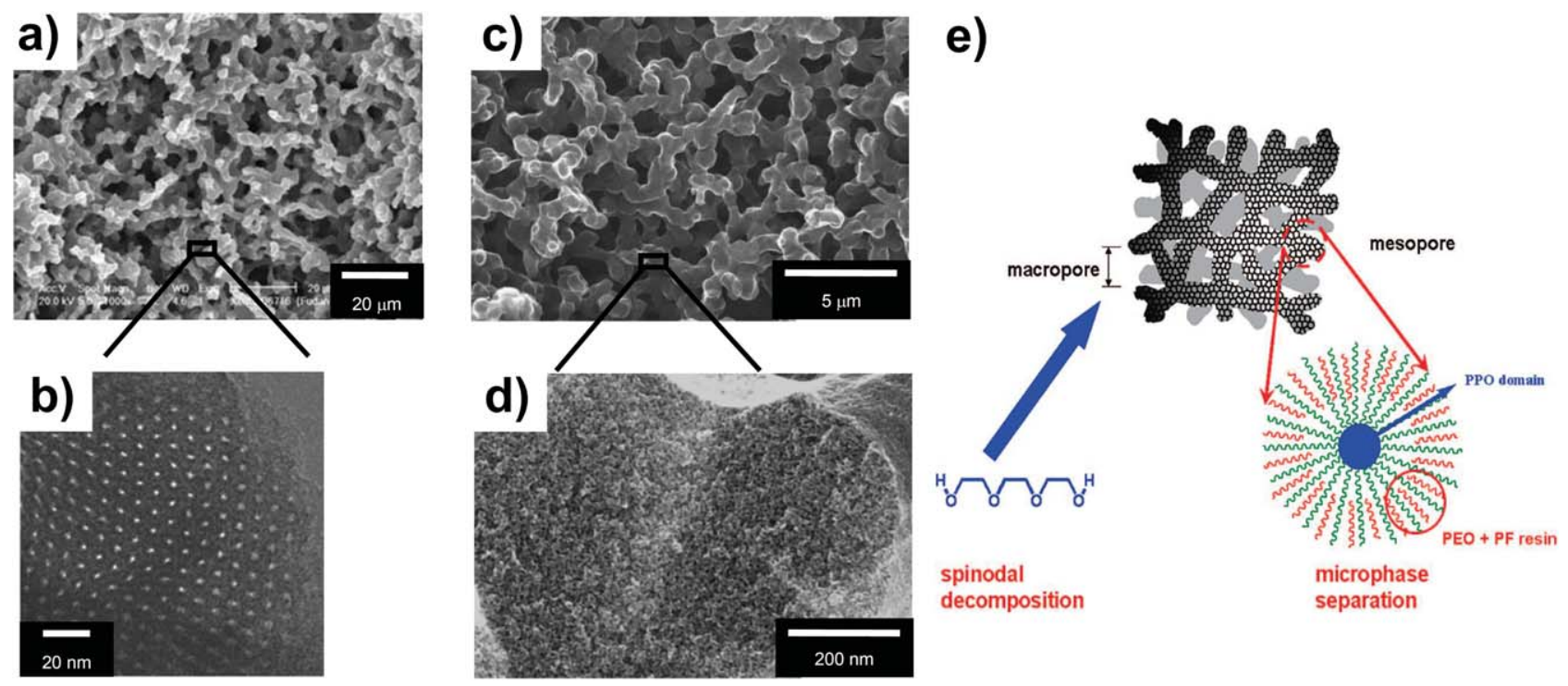

Fig. 8 Synthesis of hierarchical meso-macroporous carbon employing phase separation for macropore formation. (a) SEM image and (b) TEM image of a carbon monolith prepared by Zhao and co-workers ${ }^{71}$ from a mixture of phenol-formaldehyde, Pluronic F127 and P123 in aqueous phase under hydrothermal conditions. The imaged sample was carbonized at $600^{\circ} \mathrm{C}$. (a and b) Reproduced with permission from ref. 71. Copyright 2008, The Royal Society of Chemistry. (c-e) Carbon monolith reported by Dai and co-workers prepared using F127 as the mesopore template and EG as the solvent for spinodal decomposition. ${ }^{74}$ The sample imaged by SEM (c) and TEM (d) was carbonized at $850{ }^{\circ} \mathrm{C}$. The SEM image reveals a bicontinuous network. TEM indicates mesopores in the carbon skeleton. (e) Schematic illustration of the hierarchical meso-macroporous carbon resulting from dual phase separation. (c-e) Reproduced with permission from ref. 74. Copyright 2009, American Chemical Society. 
F127-templated mesopores of $8 \mathrm{~nm}$ in diameter. Although the occurrence of macropores was attributed to the use of glyoxal as the cross-linker, the underlying mechanism of macropore formation has not been revealed so far.

\section{Recent applications of ordered mesoporous carbons obtained through soft-templating}

Due to their unique properties, i.e. chemical stability, electronic conductivity, defined pore size, large surface area and high pore volume, ordered mesoporous carbons are increasingly applied in fields such as sorption, catalysis, energy storage and biomedicine. Zhao and co-workers studied the adsorption of bulky dye molecules from waste water, ${ }^{76,77}$ where mesoporous carbons showed adsorption capacities almost twice as high as reported for conventional activated carbon. Moreover, they also demonstrated that the surface of ordered mesoporous carbon FDU-15 can be modified by wet oxidation with acidic ammonia persulfate (APS, $\left(\mathrm{NH}_{4}\right)_{2} \mathrm{~S}_{2} \mathrm{O}_{8}$ ) and $\mathrm{HNO}_{3}$. This surface modification further improved adsorption capacities for various metal ions, fuchsin dye and ibuprofen drug, whereas the defined mesopore structure remained intact. ${ }^{77}$

Another example of surface modification was reported by Mayes et al., who treated a mesoporous carbon synthesized through the soft-templating in phosphoric acid to synthesize a mesoporous acidic catalyst. ${ }^{78}$ The derived catalyst proved to be active in isopropanol dehydration.

The application of ordered mesoporous carbons as a support for metal particles has become an interesting strategy in electrocatalysis. ${ }^{79,80}$ Besides the use as a support, mesoporous carbon can also be used as a catalyst. For instance, Wang et al. reported the modification of mesoporous carbon by ammonia treatment at temperatures between 950 and $1050{ }^{\circ} \mathrm{C}$ to produce a nitrogendoped and metal-free carbon catalyst. ${ }^{81}$ The material was reported to be active in the electrocatalytic oxygen reduction reaction (ORR).

Moreover, mesoporous carbons (both hard-templated ${ }^{\mathbf{8 2 , 8 3}}$ and soft-templated ${ }^{84}$ ) are also of interest for sulphur-carbon batteries. ${ }^{82,83}$ Liang et al. treated a carbonized mesoporous carbon prepared through the soft-templating with $\mathrm{KOH}$. The treatment resulted in bimodal porosity, i.e. in addition to the templated mesopores of $7 \mathrm{~nm}$ diameter, additional micropores of about $2 \mathrm{~nm}$ were formed. The carbon material was then loaded with elemental sulphur via solution infiltration. ${ }^{84}$ Tested as cathodes for $\mathrm{Li} / \mathrm{S}$ batteries, an initial discharge capacity as high as $1584 \mathrm{~mA} \mathrm{~h} \mathrm{~g}^{-1}$ was obtained at a high current density of $2.5 \mathrm{~A}$ $\mathrm{g}^{-1}$. Improved battery performance was attributed to the fact that micropores act as containers for elemental sulphur, whereas mesopores facilitate the transport of $\mathrm{Li}$ ions during the electrochemical cycling and accommodate polysulfides and sulphide ions.

\section{Conclusions and outlook}

Soft templating by micelles of amphiphilic block-copolymers provides facile access to the synthesis of carbon materials with defined homogeneous pore structure. Size and topology of the mesopore system can be tuned by the choice of appropriate template polymer and composition of the initial precursor solution. Moreover, swelling agents can be used to generate larger mesopores. The resin formation is critically influenced by the choice of precursor molecule, cross-linker, and the polymerization conditions. Alternative polymerization catalysts containing nitrogen provide the option to generate also nitrogendoped carbon materials in a simple one-pot synthesis. Moreover, the concept of micelle-templated mesopores can be combined with strategies of macro-pore formation, resulting in hierarchical meso-macroporous carbon materials.

To benefit practical applications further research should in addition to control over the local pore structure also address improved control over the macroscopic morphology of porous carbon, e.g. shaping into films or membranes for sensors and catalysis, monoliths for chromatography, fibres for electrical applications and nanoparticles for the biological field. 1D nanomaterials of mesoporous carbons, for instance a fibre morphology, could be promising in applications in which short paths for fast transportation of molecules are desired. ${ }^{85}$ Considering recent advances in electrospinning-syntheses of polymeric and metal oxide fibres, ${ }^{86}$ similar synthesis paths towards ordered mesoporous carbon fibres become feasible. However, for applications in the shape of carbon-based films in heterogeneous catalysis, the synthesis routes must be adapted to work also with typical wall materials of chemical reactors, i.e. stainless steels. The chemical interactions between coating solutions and the steel surface as well as the significant roughness of steel substrates will require tailored synthesis procedures as well as substrate pre-treatments. ${ }^{87}$

Besides the control over mesostructure and macroscopic morphology, the chemistry of the pore walls of ordered mesoporous carbons is equally important for many applications. Typically, carbon materials are subject to a post-synthesis modification to anchor organic functionalities, inorganic components or inorganic nanoparticles on their surface. However, adding the functional species already to the starting solution employed for the synthesis of mesoporous carbon while preserving the pore-formation mechanism will provide an elegant and promising alternative to the post-treatment methods. ${ }^{\mathbf{8 8 - 9 4}}$

Moreover, synthesis routes that enable a more facile graphitization of the carbon framework are also desirable. So far, resins of resol, resorcinol or phloroglucinol-formaldehyde are commonly employed. However, they require temperatures exceeding $2200{ }^{\circ} \mathrm{C}$ for graphitization, which significantly degrades the templated mesostructure. Hence, the search for precursors which cannot only strongly interact with the softtemplates but also convert into graphitic units at low temperatures is highly desirable. ${ }^{95}$

Finally, the mechanisms of self-assembly and the chemical interactions between precursors and templates deserve further investigation, since the mechanistic understanding can guide the rational development of improved precursors and templates and more robust synthesis strategies. ${ }^{36}$

\section{Acknowledgements}

LC and RK thank BMBF within the Nanofutur program (FKZ 03X5517A). RK also acknowledges German Cluster of Excellence in Catalysis (UNICAT) funded by the German National 
Science Foundation (DFG) and managed by the Technical University of Berlin.

\section{References}

1 A. Oya, S. Yoshida, J. Alcanizmonge and A. Linaressolano, Carbon, 1995, 33, 1085-1090.

2 T. Kyotani, Carbon, 2000, 38, 269-286.

3 J. Ozaki, N. Endo, W. Ohizumi, K. Igarashi, M. Nakahara, A. Oya, S. Yoshida and T. Iizuka, Carbon, 1997, 35, 1031-1033.

4 J. Biener, M. Stadermann, M. Suss, M. A. Worsley, M. M. Biener, K. A. Rose and T. F. Baumann, Energy Environ. Sci., 2011, 4, 656667.

5 R. Ryoo, S. H. Joo and S. Jun, J. Phys. Chem. B, 1999, 103, 77437746.

6 R. Ryoo, S. H. Joo, M. Kruk and M. Jaroniec, Adv. Mater., 2001, 13, 677-681.

7 J. Lee, S. Han and T. Hyeon, J. Mater. Chem., 2004, 14, 478-486.

8 H. F. Yang and D. Y. Zhao, J. Mater. Chem., 2005, 15, 1217-1231.

9 B. Sakintuna and Y. Yurum, Ind. Eng. Chem. Res., 2005, 44, 2893 2902.

10 A. H. Lu and F. Schüth, Adv. Mater., 2006, 18, 1793-1805.

11 J. Lee, J. Kim and T. Hyeon, Adv. Mater., 2006, 18, 2073-2094.

12 C. D. Liang, Z. J. Li and S. Dai, Angew. Chem., Int. Ed., 2008, 47, 3696-3717.

13 F. B. Su, Z. C. Zhou, W. P. Guo, J. J. Liu, X. N. Tian and X. S. Zhao, in Chemistry and Physics of Carbon, Crc Press-Taylor \& Francis Group, Boca Raton, 2008, vol. 30, pp. 63-128.

14 A. Stein, Z. Y. Wang and M. A. Fierke, Adv. Mater., 2009, 21, 265293.

15 Y. D. Xia, Z. X. Yang and R. Mokaya, Nanoscale, 2010, 2, 639-659.

16 E. Ortel, A. Fischer, L. Chuenchom, J. Polte, F. Emmerling, B. Smarsly and R. Kraehnert, Small, 2012, 8, 298-309.

17 C. D. Liang, K. L. Hong, G. A. Guiochon, J. W. Mays and S. Dai, Angew. Chem., Int. Ed., 2004, 43, 5785-5789.

18 Y. Wan, Y. F. Shi and D. Y. Zhao, Chem. Mater., 2008, 20, 932-945.

19 P. Van der Voort, C. Vercaemst, D. Schaubroeck and F. Verpoort, Phys. Chem. Chem. Phys., 2008, 10, 347-360.

20 Z. Y. Wang, F. Li, N. S. Ergang and A. Stein, Chem. Mater., 2006, 18, $5543-5553$.

21 Y. R. Liang, D. C. Wu and R. W. Fu, Langmuir, 2009, 25, 7783-7785.

22 Y. H. Deng, C. Liu, T. Yu, F. Liu, F. Q. Zhang, Y. Wan, L. J. Zhang, C. C. Wang, B. Tu, P. A. Webley, H. T. Wang and D. Y. Zhao, Chem. Mater., 2007, 19, 3271-3277.

23 H. J. Liu, W. J. Cui, L. H. Jin, C. X. Wang and Y. Y. Xia, J. Mater Chem., 2009, 19, 3661-3667.

24 C. D. Liang and S. Dai, J. Am. Chem. Soc., 2006, 128, 5316-5317.

25 F. Q. Zhang, Y. Meng, D. Gu, Y. Yan, C. Z. Yu, B. Tu and D. Y. Zhao, J. Am. Chem. Soc., 2005, 127, 13508-13509.

26 C. Y. Liu, L. X. Li, H. H. Song and X. H. Chen, Chem. Commun., 2007, 757-759.

27 Y. H. Deng, T. Yu, Y. Wan, Y. F. Shi, Y. Meng, D. Gu, L. J. Zhang, Y. Huang, C. Liu, X. J. Wu and D. Y. Zhao, J. Am. Chem. Soc., 2007, 129, 1690-1697.

28 Y. Meng, D. Gu, F. Q. Zhang, Y. F. Shi, H. F. Yang, Z. Li, C. Z. Yu, B. Tu and D. Y. Zhao, Angew. Chem., Int. Ed., 2005, 44, 70537059.

29 Y. Meng, D. Gu, F. Q. Zhang, Y. F. Shi, L. Cheng, D. Feng, Z. X. Wu, Z. X. Chen, Y. Wan, A. Stein and D. Y. Zhao, Chem. Mater., 2006, 18, 4447-4464.

30 S. Tanaka, Y. Katayama, M. P. Tate, H. W. Hillhouse and Y. Miyake, J. Mater. Chem., 2007, 17, 3639-3645.

31 G. J. D. Soler-illia, C. Sanchez, B. Lebeau and J. Patarin, Chem. Rev., 2002, 102, 4093-4138.

32 Y. Wan and D. Y. Zhao, Chem. Rev., 2007, 107, 2821-2860.

33 Q. S. Huo, D. I. Margolese, U. Ciesla, P. Y. Feng, T. E. Gier, P. Sieger, R. Leon, P. M. Petroff, F. Schüth and G. D. Stucky, Nature, 1994, 368, 317-321.

34 G. Soler-Illia and P. Innocenzi, Chem.-Eur. J., 2006, 12, 4478-4494. 35 X. Q. Wang, C. D. Liang and S. Dai, Langmuir, 2008, 24, 7500-7505.

36 M. Florent, C. Xue, D. Zhao and D. Goldfarb, Chem. Mater., 2012, 24, 383-392.

37 H. Kosonen, J. Ruokolainen, P. Nyholm and O. Ikkala, Macromolecules, 2001, 34, 3046-3049.
38 S. Valkama, A. Nykanen, H. Kosonen, R. Ramani, F. Tuomisto, P. Engelhardt, G. ten Brinke, O. Ikkala and J. Ruokolainen, $A d v$. Funct. Mater., 2007, 17, 183-190.

39 E. Fitzer, K. H. Kochling, H. P. Boehm and H. Marsh, Pure Appl. Chem., 1995, 67, 473-506.

40 W. Ruland and B. Smarsly, J. Appl. Crystallogr., 2002, 35, 624-633.

41 Y. S. Hu, P. Adelhelm, B. M. Smarsly, S. Hore, M. Antonietti and J. Maier, Adv. Funct. Mater., 2007, 17, 1873-1878.

42 G. A. Zickler, B. Smarsly, N. Gierlinger, H. Peterlik and O. Paris, Carbon, 2006, 44, 3239-3246.

43 H. Kosonen, S. Valkama, A. Nykanen, M. Toivanen, G. ten Brinke, J. Ruokolainen and O. Ikkala, Adv. Mater., 2006, 18, 201-205.

44 S. Tanaka, N. Nishiyama, Y. Egashira and K. Ueyama, Chem. Commun., 2005, 2125-2127.

45 D. H. Long, W. M. Qiao, L. Zhan, X. Y. Liang and L. C. Ling, Microporous Mesoporous Mater., 2009, 121, 58-66.

46 S. Tanaka, A. Doi, N. Nakatani, Y. Katayama and Y. Miyake, Carbon, 2009, 47, 2688-2698.

47 J. Jin, N. Nishiyama, Y. Egashira and K. Ueyama, Microporous Mesoporous Mater., 2009, 118, 218-223.

48 J. Gorka, C. Fenning and M. Jaroniec, Colloids Surf., A, 2009, 352, $113-117$.

49 S. Kataoka, T. Yamamoto, Y. Inagi, A. Endo, M. Nakaiwa and T. Ohmori, Carbon, 2008, 46, 1358-1360.

50 J. Jin, T. Mitome, Y. Egashira and N. Nishiyama, Colloids Surf., A, 2011, 384, 58-61.

51 M. J. Xie, H. H. Dong, D. D. Zhang, X. F. Guo and W. P. Ding, Carbon, 2011, 49, 2459-2464.

52 P. Li, Y. Song, Q. G. Guo, J. L. Shi and L. Liu, Mater. Lett., 2011, 65, $2130-2132$

53 X. F. Qian, H. X. Li and Y. Wan, Microporous Mesoporous Mater., 2011, 141, 26-37.

54 U. B. Suryavanshi, T. Ijima, A. Hayashi, Y. Hayashi and M. Tanemura, Chem. Commun., 2011, 47, 10758-10760.

55 Y. Huang, J. P. Yang, H. Q. Cai, Y. P. Zhai, D. Feng, Y. H. Deng, B. Tu and D. Y. Zhao, J. Mater. Chem., 2009, 19, 6536-6541.

56 Y. Huang, H. Q. Cai, T. Yu, F. Q. Zhang, F. Zhang, Y. Meng, D. Gu, Y. Wan, X. L. Sun, B. Tu and D. Y. Zhao, Angew. Chem., Int. Ed., 2007, 46, 1089-1093.

57 Y. H. Deng, Y. Cai, Z. K. Sun, D. Gu, J. Wei, W. Li, X. H. Guo, J. P. Yang and D. Y. Zhao, Adv. Funct. Mater., 2010, 20, 3658-3665.

58 J. Y. Zhang, Y. H. Deng, J. Wei, Z. K. Sun, D. Gu, H. Bongard, C. Liu, H. H. Wu, B. Tu, F. Schüth and D. Y. Zhao, Chem. Mater., 2009, 21, 3996-4005.

59 X. Y. Liu, B. Z. Tian, C. Z. Yu, F. Gao, S. H. Xie, B. Tu, R. C. Che, L. M. Peng and D. Y. Zhao, Angew. Chem., Int. Ed., 2002, 41, 38763878 .

60 J. Fan, C. Z. Yu, J. Lei, Q. Zhang, T. C. Li, B. Tu, W. Z. Zhou and D. Y. Zhao, J. Am. Chem. Soc., 2005, 127, 10794-10795.

61 S. N. Che, A. E. Garcia-Bennett, X. Y. Liu, R. P. Hodgkins, P. A. Wright, D. Y. Zhao, O. Terasaki and T. Tatsumi, Angew. Chem., Int. Ed., 2003, 42, 3930-3934.

62 Y. Q. Wang, C. M. Yang, B. Zibrowius, B. Spliethoff, M. Linden and F. Schüth, Chem. Mater., 2003, 15, 5029-5035.

63 Y. H. Deng, J. Liu, C. Liu, D. Gu, Z. K. Sun, J. Wei, J. Y. Zhang, L. J. Zhang, B. Tu and D. Y. Zhao, Chem. Mater., 2008, 20, 72817286.

64 Y. Deng, C. Liu, D. Gu, T. Yu, B. Tu and D. Zhao, J. Mater. Chem., 2008, 18, 91-97.

65 A. H. Lu, B. Spliethoff and F. Schüth, Chem. Mater., 2008, 20, 5314 5319.

66 G. P. Hao, W. C. Li, D. Qian, G. H. Wang, W. P. Zhang, T. Zhang, A. Q. Wang, F. Schüth, H. J. Bongard and A. H. Lu, J. Am. Chem. Soc., 2011, 133, 11378-11388.

67 G. P. Hao, W. C. Li, S. A. Wang, G. H. Wang, L. Qi and A. H. Lu, Carbon, 2011, 49, 3762-3772.

68 S. Kubo, R. J. White, N. Yoshizawa, M. Antonietti and M. M. Titirici, Chem. Mater., 2011, 23, 4882-4885.

69 A. T. Rodriguez, X. F. Li, J. Wang, W. A. Steen and H. Y. Fan, Adv. Funct. Mater., 2007, 17, 2710-2716.

70 Z. Y. Wang, E. R. Kiesel and A. Stein, J. Mater. Chem., 2008, 18, 2194-2200.

71 Y. Huang, H. Q. Cai, D. Feng, D. Gu, Y. H. Deng, B. Tu, H. T. Wang, P. A. Webley and D. Y. Zhao, Chem. Commun., 2008, $2641-2643$ 
72 K. Nakanishi, Y. Kobayashi, T. Amatani, K. Hirao and T. Kodaira, Chem. Mater., 2004, 16, 3652-3658.

73 T. Amatani, K. Nakanishi, K. Hirao and T. Kodaira, Chem. Mater., 2005, 17, 2114-2119.

74 C. D. Liang and S. Dai, Chem. Mater., 2009, 21, 2115-2124.

75 R. T. Mayes, C. Tsouris, J. O. Kiggans, S. M. Mahurin, D. W. DePaoli and S. Dai, J. Mater. Chem., 2010, 20, 8674-8678.

76 X. Zhuang, Y. Wan, C. M. Feng, Y. Shen and D. Y. Zhao, Chem. Mater., 2009, 21, 706-716.

77 Z. X. Wu, P. A. Webley and D. Y. Zhao, Langmuir, 2010, 26, 1027710286.

78 R. T. Mayes, P. F. Fulvio, Z. Ma and S. Dai, Phys. Chem. Chem. Phys., 2011, 13, 2492-2494.

79 M. C. Orilall, F. Matsumoto, Q. Zhou, H. Sai, H. D. Abruna, F. J. DiSalvo and U. Wiesner, J. Am. Chem. Soc., 2009, 131, 93899395.

80 N. Menzel, E. Ortel, R. Kraehnert and P. Strasser, ChemPhysChem, 2012, 13, 1385-1394.

81 X. Q. Wang, J. S. Lee, Q. Zhu, J. Liu, Y. Wang and S. Dai, Chem. Mater., 2010, 22, 2178-2180.

82 X. L. Ji, K. T. Lee and L. F. Nazar, Nat. Mater., 2009, 8, 500-506.

83 G. He, X. L. Ji and L. Nazar, Energy Environ. Sci., 2011, 4, 28782883.
84 C. D. Liang, N. J. Dudney and J. Y. Howe, Chem. Mater., 2009, 21, $4724-4730$.

85 K. X. Wang, Y. G. Wang, Y. R. Wang, E. Hosono and H. S. Zhou, J. Phys. Chem. C, 2009, 113, 1093-1097.

86 C. Wessel, R. Ostermann, R. Dersch and B. M. Smarsly, J. Phys. Chem. C, 2011, 115, 362-372.

87 S. Sokolov, E. Ortel, J. Radnik and R. Kraehnert, Thin Solid Films, 2009, 518, 27-35.

88 J. H. Zhou, J. P. He, T. Wang, D. Sun, G. W. Zhao, X. Chen, D. J. Wang and Z. Y. Di, J. Mater. Chem., 2008, 18, 5776-5781.

89 R. Liu, Y. Ren, Y. Shi, F. Zhang, L. Zhang, B. Tu and D. Zhao, Chem. Mater., 2008, 20, 1140-1146.

90 J. Gorka and M. Jaroniec, J. Phys. Chem. C, 2008, 112, 11657-11660.

91 J. Gorka and M. Jaroniec, J. Phys. Chem. C, 2010, 114, 6298-6303.

92 X. C. Zhao, A. Q. Wang, J. W. Yan, G. Q. Sun, L. X. Sun and T. Zhang, Chem. Mater., 2010, 22, 5463-5473.

93 L. She, J. Li, Y. Wan, X. D. Yao, B. Tu and D. Y. Zhao, J. Mater. Chem., 2011, 21, 795-800.

94 M. Z. Dai, L. Y. Song, J. T. LaBelle and B. D. Vogt, Chem. Mater., 2011, 23, 2869-2878.

95 P. F. Fulvio, R. T. Mayes, X. Q. Wang, S. M. Mahurin, J. C. Bauer, V. Presser, J. McDonough, Y. Gogotsi and S. Dai, Adv. Funct. Mater., 2011, 21, 2208-2215. 